University of Nebraska - Lincoln

DigitalCommons@University of Nebraska - Lincoln

Effects of refuges on the evolution of resistance to transgenic corn by the western corn rootworm, Diabrotica virgifera virgifera LeConte

\author{
Jennifer Deitloff \\ lowa State University; Lock Haven University \\ Mike W. Dunbar \\ lowa State University \\ David A. Ingber \\ lowa State University \\ Bruce E. Hibbard \\ USDA-ARS, University of Missouri, bruce.hibbard@ars.usda.gov \\ Aaron J. Gassmann \\ lowa State University
}

Follow this and additional works at: https://digitalcommons.unl.edu/usdaarsfacpub

Part of the Agriculture Commons, Biochemistry, Biophysics, and Structural Biology Commons, and the Environmental Sciences Commons

Deitloff, Jennifer; Dunbar, Mike W.; Ingber, David A.; Hibbard, Bruce E.; and Gassmann, Aaron J., "Effects of refuges on the evolution of resistance to transgenic corn by the western corn rootworm, Diabrotica virgifera virgifera LeConte" (2015). Publications from USDA-ARS / UNL Faculty. 1519.

https://digitalcommons.unl.edu/usdaarsfacpub/1519

This Article is brought to you for free and open access by the U.S. Department of Agriculture: Agricultural Research Service, Lincoln, Nebraska at DigitalCommons@University of Nebraska - Lincoln. It has been accepted for inclusion in Publications from USDA-ARS / UNL Faculty by an authorized administrator of DigitalCommons@University of Nebraska - Lincoln. 


\title{
Effects of refuges on the evolution of resistance to transgenic corn by the western corn rootworm, Diabrotica virgifera virgifera LeConte
}

\author{
Jennifer Deitloff, ${ }^{\text {a,b* }}{ }^{*}$ Mike W Dunbar, ${ }^{a}$ David A Ingber, ${ }^{a}$ Bruce E Hibbard $^{c}$ \\ and Aaron J Gassmann ${ }^{a}$
}

\begin{abstract}
BACKGROUND: Diabrotica virgifera virgifera LeConte is a major pest of corn and causes over a billion dollars of economic loss annually through yield reductions and management costs. Corn producing toxins derived from Bacillus thuringiensis (Bt) has been developed to help manage $D$. v. virgifera. However, previous studies have demonstrated the ability of this species to evolve resistance to $B t$ toxins in both laboratory and field settings.

RESULTS: We used an experimental evolution approach to test the refuge strategies for delaying resistance of $D$. $v$. virgifera to corn producing $B t$ toxin Cry34/35Ab1. In the absence of refuges, $D$. v. virgifera developed resistance to $B t$ corn after three generations of selection. In some cases, non-Bt refuges reduced the level of resistance compared with the strain selected in the absence of refuges, but refuge strains did show reduced susceptibility to Bt corn compared with the unselected strain.

CONCLUSIONS: In this study, non-Bt refuges delayed resistance to Bt corn by $D$. v. virgifera in some cases but not others. Combining the refuge strategy with pyramids of multiple Bt toxins and applying other pest management strategies will likely be necessary to delay resistance of $D$. v. virgifera to $B t$ corn.

(c) 2015 Society of Chemical Industry
\end{abstract}

Keywords: agriculture; insect resistance management; refuge strategy; transgenic crops

\section{INTRODUCTION}

Genetically engineered crops that produce insecticidal toxins derived from Bacillus thuringiensis $(B t)$ have been commercially available since $1996 .{ }^{1}$ In 2013, 76\% of the corn (Zea mays L.) planted in the United States produced Bt toxins to manage potentially damaging insect pests. ${ }^{2}$ The benefits of $B t$ crops include effective management of pests and reduced reliance on conventional insecticides. ${ }^{3,4}$ Diabrotica virgifera virgifera LeConte, western corn rootworm, is a key pest of corn and is one of the pests targeted by $B t$ corn. Over a billion dollars is lost annually to $D$. v. virgifera from yield reductions and costs associated with management. ${ }^{5}$ Currently, four $B t$ toxins are commercially available for management of D. v. virgifera (Cry3Bb1, Cry34/35Ab1, mCry3A and eCry3.1Ab), and these are sold in corn hybrids either singly or as pyramids. ${ }^{6}$

D. $v$. virgifera has demonstrated its ability to adapt to several management strategies, including chemical insecticides, ${ }^{7,8}$ crop rotation ${ }^{9}$ and Bt corn. ${ }^{10-13}$ Rapid adoption of Bt crops by farmers has led to concerns about the evolution of $B t$ resistance. ${ }^{14-17}$ Computer models of the evolution of resistance to $B t$ corn by $D . v$. virgifera predicted resistance in as few as 3 years in some cases, ${ }^{15}$ and this is concordant with the evolution of $B t$ resistance in laboratory selection experiments and among field populations. ${ }^{10,18}$ Thus far, D. v. virgifera has evolved resistance to each of the four
$B t$ toxins in the laboratory, ${ }^{18-21}$ and field-evolved resistance has been documented to Cry3Bb1 and mCry3A. ${ }^{10-13}$

Several management strategies have been proposed to delay the evolution of resistance to $B t$ crops by insect pests. ${ }^{1,22-24}$ One tactic is the refuge strategy. This strategy uses refuges of non- $B t$ plants to provide a habitat favorable for the development of Bt-susceptible insects. ${ }^{1}$ Mating between susceptible adults emerging from the refuge and resistant adults emerging from $B t$ plants produces heterozygous progeny. To the extent that these heterozygous progeny have reduced fitness on Bt crops compared with their homozygous resistant parent, delays in resistance may be achieved. For single $B t$ toxins, the refuge strategy is most effective when it is coupled with the high-dose strategy, in which the crop produces sufficient $B t$ toxin to render survival on the

\footnotetext{
* Correspondence to: Jennifer Deitloff, East Campus Science Center 204, Biological Sciences, Lock Haven University, Lock Haven, PA 17745, USA. E-mail:jmd240@lhup.edu

a Department of Entomology, lowa State University, Ames, IA, USA

b Department of Biological Sciences, Lock Haven University, Lock Haven, PA, USA

c USDA-ARS, University of Missouri, Columbia, MO, USA
} 
$B t$ crop a functionally recessive trait. ${ }^{25}$ This occurs when the $B t$ crop kills $99.99 \%$ of susceptible individuals or produces 25 times the amount needed to kill a susceptible pest. ${ }^{25}$ However, none of the Bt toxins commercialized to manage $D$. v. virgifera are considered high dose, ${ }^{11,26-31}$ and resistance to $B t$ toxin in $D$. v. virgifera is not recessive, ${ }^{18,32}$ which increases the risk of this pest evolving resistance to $B t$ corn and thereby raises concerns about the effectiveness of refuges in delaying resistance.

Non- $B t$ refuge plants can be grown in either a structured refuge (i.e. a block of non-Bt plants) or an integrated refuge (i.e. a seed blend of $B t$ and non-Bt plants). In a block refuge, a section of the field contains non-Bt host plants, while the remainder of the field contains $B t$ plants. In a blended refuge, non- $B t$ seeds are mixed with $B t$ seeds and planted throughout a field. Several models have evaluated the efficacy of these two strategies for delaying the evolution of resistance. ${ }^{22,23}$ Under most scenarios examined, both refuge strategies delay resistance considerably when compared with the absence of a refuge. ${ }^{23}$ However, comparisons between block-refuge and blended-refuge strategies with computer models have produced mixed results as to which delays resistance longer, with outcomes depending on aspects of pest biology and the Bt crops, including dose of the $B t$ toxin, dispersal of adult insects and interplant movement of larval insects. $^{23,33}$

Here, we used an experimental evolution approach to test whether delays in evolution of resistance may be achieved with refuges when a $B t$ crop is not high dose. We compared four insect treatments, each represented by one insect strain: two treatments tested refuge strategies (a seed blend and a block refuge), a third treatment was a strain selected in the absence of refuges and the final treatment was an unselected strain, in which insects were never exposed to $B t$ toxin. We tested these treatments using a laboratory strain of $D$. v. virgifera and a transgenic corn hybrid that produced Bt toxin Cry34/35Ab1 (event DAS-59122-7). To examine the evolution of resistance to this toxin, we measured survival of $D$. v. virgifera to adulthood and the delay in larval development experienced by insects fed Cry34/35Ab1 corn. Measuring delays in larval development is a relevant metric for quantifying resistance to corn producing $B t$ toxin Cry34/35Ab1, because it is highly correlated with the capacity of $D$. v. virgifera to survive to adulthood on Cry34/35Abl corn. ${ }^{19,34}$ Measurements of larval developmental rate are currently used as a technique to monitor resistance to Cry34/35Ab1 corn in field populations of D. v. virgifera. ${ }^{34}$ The results of this study provide insights into the potential for refuges to delay resistance for $B t$ crops that do not produce a high dose of toxin.

\section{METHODS}

\subsection{Strain development}

Populations of $D$. v. virgifera were collected from Caledonia, Minnesota and Janesville, Wisconsin, in 2004 (see Meihls et al. ${ }^{35}$ for additional details), and from Dodge City, Kansas, in 2002 (see Meihls et al. ${ }^{18}$ for additional details). These populations were crossed with a non-diapausing strain of $D$. v. virgifera ${ }^{36,37}$ obtained from the USDA-ARS Northern Central Agricultural Research Laboratory and then pooled into one strain, referred to as the pooled strain hereafter. The development of this pooled strain occurred at the USDA-ARS Plant Genetics Research Laboratory in Columbia, Missouri, and was completed in November 2009. The pooled, non-diapausing strain was transferred to lowa State University in February 2010.

\subsection{Strain rearing}

Insects were reared for two generations on small seedling mats followed by large seedling mats of non-Bt corn (Pioneer hybrid 35 F38) using methods described by Jackson. ${ }^{38}$ Small seedling mats were produced by soaking $40 \mathrm{~mL}$ of corn seeds in water for $24 \mathrm{~h}$ and placing these presoaked seeds in $0.95 \mathrm{~L}$ plastic deli containers with lids (Pactiv Showcase; Johnson Paper and Supply Co., Minneapolis, MN), adding $60 \mathrm{~mL}$ of water, and then covering the seeds and water with $200 \mathrm{~g}$ of soil. Soil consisted of a 1:1 mixture of potting soil (Sunshine Mix No. 1; Sungro, Bellevue, WA) and thoroughly dried field soil collected from lowa State University's Johnson Research Farm in Ames, lowa. We then added 600 D. v. virgifera eggs ( 1 week old) that were suspended in a $0.15 \%$ agar solution. Eggs hatched approximately 1 week thereafter. Approximately 1 week after eggs hatched, we transferred larvae to large seedling mats by removing small seedling mats from containers, inverting two small seedling mats and placing them on top of a larger seedling mat. These larger seedling mats were made in $21 \times 27 \times 10 \mathrm{~cm}(L \times W \times H)$ plastic containers (Rubbermaid, Fairlawn, $\mathrm{OH}$ ) by adding $150 \mathrm{~mL}$ of presoaked corn seeds (soaked in water for $24 \mathrm{~h}$ ) to $150 \mathrm{~mL}$ of water, and then covering the water and seeds with $2000 \mathrm{~mL}$ of soil. The entire contents of the container (two inverted smaller seeding mats plus larger seedling mat) were covered with mesh fabric and a lid.

We collected newly emerged adults from large seedling mats $5-6$ times per week and placed adults in $18 \mathrm{~cm} \times 18 \mathrm{~cm} \times 18 \mathrm{~cm}$ $(L \times W \times H)$ mesh cages (Megaview Science, Taiwan). Adults were provided with $1.5 \%$ solid agar as a source of water, corn leaf tissue and a complete adult diet (F976H8B-M; Bio-Serv, Flemington, NJ, USA), and these were changed 4-5 times per week. We provided adults with an ovipositional substrate that consisted of moistened $180 \mu \mathrm{m}$ sieved soil placed in $10 \mathrm{~cm}$ petri dishes, referred to hereafter as oviposition dishes, and these were changed twice per week. Eggs were collected from oviposition dishes by washing the $180 \mu \mathrm{m}$ sieved soil and eggs in a $250 \mu \mathrm{m}$ sieve. All mesh cages and seedling mats were kept in environmental chambers $\left(25^{\circ} \mathrm{C}\right.$, 16:8 L:D).

\subsection{Strain selection}

Four treatments were compared: unselected, block refuge, blended refuge and pure Bt. To accomplish this, the pooled strain was divided into four separate strains in June 2010, with each strain corresponding to one of the four treatments. Whenever possible, population size was $1200-1600$ adults per strain per generation. The unselected strain was never exposed to $B t$ corn during rearing. The three other strains were selected on seedling mats that contained Bt corn. The Bt hybrid used was Pioneer hybrid 35 F44, which expresses event DAS-59122-7 and produces the $B t$ binary toxin Cry34Ab1/Cry35Ab1. The unselected strain was reared on seedling mats of non-Bt corn, Pioneer hybrid 35 F38, which is the near-isoline of the $B t$ hybrid used for the selected strains. For both hybrids there was no insecticidal or fungicidal seed treatment on seeds. These same corn hybrids were used throughout this experiment and are referred to as Bt corn and non-Bt corn respectively. To ensure that the Pioneer hybrid 35 F44 expressed DAS-59122-7 and produced Bt toxin Cry34/35Ab1, we confirmed the presence of Cry34/35Ab1 in corn tissues each generation with ELISA (QuickStix kit; Envirologix, Portland, Maine). Each generation, a few seedlings from seven seedling mats were selected at random and tested for Cry34/35Ab1, and in all cases corn tissue contained this $B t$ toxin. Similarly, each generation we 
randomly sampled seven seedling mats of Pioneer hybrid 35 F38 (non-Bt corn) and never found the presence of $B t$ toxin.

The unselected strain was reared on seedling mats of non- $B t$ corn. The block-refuge strain was propagated on the basis of field data for the number of insects emerging from $B t$ corn and non-Bt corn (see below). Insects from the block-refuge strain were reared on seedling mats composed entirely of $B t$ corn; however, when newly emerging adults were placed in a mesh cage, they were combined with newly emerging adults from the unselected strain, which simulated the addition of adults from a non- $B t$ refuge. Newly emerging adults from the block-refuge strain and unselected strain were combined in a 1:9 ratio each day, which is based on the ratio of adult survival observed in the field for Cry34/35Ab1 corn and a 20\% refuge of non-Bt corn. ${ }^{27}$ Specifically, Storer et al. ${ }^{27}$ reported a ratio of 1:36 for survival on Cry34/35Ab1 corn compared with non-Bt corn; in a landscape that was $80 \% B t$ corn and $20 \%$ non-Bt corn (the current block-refuge requirement single-trait $B t$ corn targeting rootworm ${ }^{6}$ ), this would translate to a ratio of 1:9 for insects from Cry34/35Ab1 corn compared with non-Bt corn. Because we were interested in effects of refuges on resistance evolution, and not effects related to dispersal and timing of emergence (even though these factors can have a considerable impact on resistance evolution), this ratio of insects was added to the mesh cage each day to remove any potential differences in the timing of mating and emergence between the two strains. The blended-refuge strain was propagated in a blended refuge produced by using seedling mats composed of 90\% Bt corn and 10\% non-Bt corn (percentages measured by volume of seeds). This is based on the $10 \%$ refuge currently used in the field for Cry34/35Ab1 corn with a blended refuge. ${ }^{39}$ The pure-Bt strain was a positive control and was reared on seedling mats of only Bt corn. Except for the block-refuge strain as described above, adult insects for each strain were added to mesh cages directly from the seedling mats from which they emerged.

In order to ensure that a sufficient number of adults were available to maintain strains and to conduct bioassays, unselected generations were reared intermittently throughout the experiment. During these unselected generations, all four strains were reared on non-Bt corn (hybrid 35 F44). The unselected strain was reared on non-Bt corn during all generations. For the block-refuge, blended-refuge and pure- $B t$ strains there were nine generations of selection (i.e. larvae were reared on $B t$ corn as described above): $\mathrm{F} 1, \mathrm{F3}, \mathrm{F} 4, \mathrm{F5}, \mathrm{F} 8, \mathrm{~F} 9, \mathrm{~F} 10, \mathrm{~F} 11$ and F13; there were five generations when these strains were not selected (i.e. larvae from all strains were reared on non-Bt corn): F2, F6, F7, F12 and F14.

During rearing of these strains, we placed approximately 600 eggs on the small seedling mats of non-Bt corn and 1200-1800 eggs on small seedling mats containing $B t$ corn. This was done to account for lower larval survival on $B t$ corn compared with non- $B t$ corn. For each generation, we collected data on the proportion of eggs that produced adults (survival) and the number of days between oviposition and emergence of adults (days to emergence).

\subsection{Larval development bioassay}

Seedling mats for the larval bioassay were produced in a manner identical to that used to generate small seedling mats. A subsample of eggs from each of the four strains was used for these bioassays, and larvae from these bioassays were never returned to the strains. Each strain was tested on seedling mats that were composed completely of either Bt corn (hybrid $35 \mathrm{~F} 44$ ) or non-Bt corn (hybrid $35 \mathrm{~F} 38$ ). The seedling mats were allowed to develop for approximately 1 week in environmental chambers $\left(25^{\circ} \mathrm{C}\right.$, 16:8 L:D) before neonate larvae were placed in seedling mats.

For all four strains, we placed newly hatched neonate larvae (less than $24 \mathrm{~h}$ old) on corn roots within seedling mats, and larvae from each strain were placed onto paired $B t$ and non-Bt seedling mats. We placed either 30 (F5-F7) or 25 (F10, F14) neonate larvae on each seedling mat. Seedling mats with larvae were held in an environmental chamber for 12 days $\left(25^{\circ} \mathrm{C}, 16: 8 \mathrm{~L}: \mathrm{D}\right)$, and $50 \mathrm{~mL}$ of water was added after 7 days.

After 12 days in an environmental chamber, we removed seedling mats with larvae and soil from the plastic containers and placed them on Berlese funnels for 4 days to extract larvae. Larvae were collected into $15 \mathrm{~mL}$ glass vials containing $85 \%$ ethanol, which killed larvae and preserved larval cadavers. For each seedling mat, we recorded the total number of larvae and larval instars (based on Hammack et $\mathrm{al} .{ }^{40}$ ). Bioassays were conducted for F5, F6, F7, F10 and F14. Because no selection occurred between F5, F6 and F7, we pooled the bioassay data for these three generations to increase statistical power.

Sample sizes varied among strains because of differences in the availability of neonate larvae for placement on seedling mats and because ethanol evaporated from vials that held larvae from five seedling mats (evaporation of ethanol and subsequent desiccation of samples meant that larvae could not be counted accurately and instars could not be determined). For bioassays of F5, F6 and $F 7$, the sample sizes for pairs of $B t$ and non-Bt seedling mats were as follows: unselected strain $=32$, block-refuge strain $=27$, blended-refuge strain $=30$, and pure- $B t$ strain $=29$, for a total of 236 seedling mats. For F10, the sample sizes were as follows: unselected strain $=19$, block-refuge strain $=20$, blended-refuge strain $=18$, and pure- $B t$ strain $=20$, for a total of 154 seedling mats. For F14, the sample sizes were as follows: unselected strain $=14$, block-refuge strain $=18$, blended-refuge strain $=20$, and pure- $B t$ strain $=20$, for a total of 144 seedling mats.

\subsection{Adult survival bioassays}

For F14, we conducted a bioassay measuring survival to adulthood. As above, a subsample of eggs from the four strains was used for these bioassays, and adults from bioassays were never returned to the strains. Each strain was tested on Bt corn and non-Bt corn. We generated seedling mats in $500 \mathrm{~mL}$ cups (Placon Corporation, Madison, WI), using $25 \mathrm{~mL}$ of presoaked corn seed (soaked in water for $24 \mathrm{~h}$ ), $40 \mathrm{~mL}$ of water and $200 \mathrm{~mL}$ of soil (the same composition as used for seedling mats) and allowing corn plants to grow for 1 week in an environmental chamber $\left(25^{\circ} \mathrm{C}, 16: 8 \mathrm{~L}: \mathrm{D}\right)$. After 1 week, we added 15 newly hatched neonate larvae (less than $24 \mathrm{~h}$ old) from one of the four experimental strains. Larvae from each strain were placed on 20 pairs of $B t$ and non-Bt seedling mats. After 6 days, we prepared larger seedling mats in $0.95 \mathrm{~L}$ plastic deli trays (the same as those used for rearing and larval assays), combining $40 \mathrm{~mL}$ of presoaked corn seeds, $60 \mathrm{~mL}$ of water and $300 \mathrm{~mL}$ of soil. These seedling mats grew for 6 days, after which seedling mats from $500 \mathrm{~mL}$ cups were removed from containers, inverted and placed on seedling mats in $0.95 \mathrm{~L}$ trays. Each seedling mat from $500 \mathrm{~mL}$ cups was added to a $0.95 \mathrm{~L}$ tray of the same type of corn (Bt or non-Bt), and $500 \mathrm{~mL}$ cups were carefully inspected to ensure that all larvae were transferred. Insects were then allowed to develop to adulthood.

We collected newly emerging adults from each container 3 times per week. We recorded the total number of adults that emerged and the day on which each adult was collected. Owing to differences in available neonate larvae in some strains, sample 

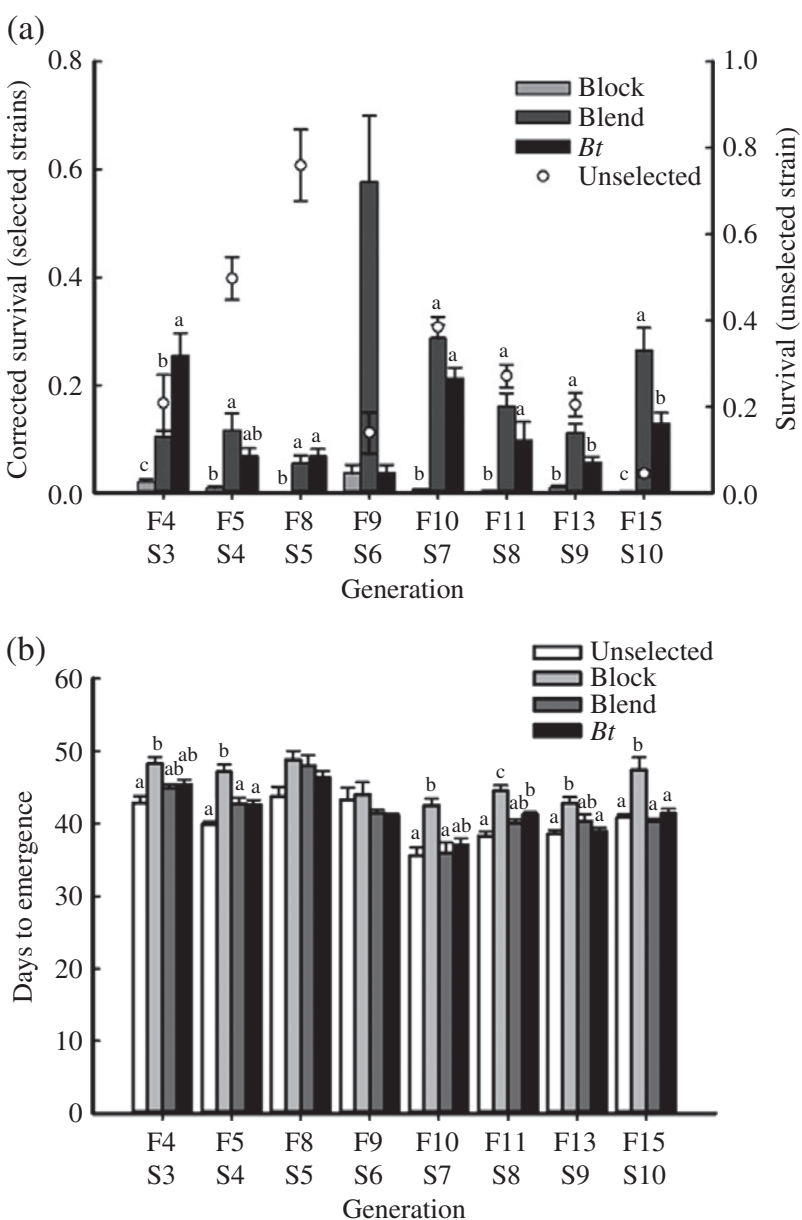

Figure 1. Survival (a) and timing of adult emergence (b) for strains during laboratory rearing. For pure- $B t$, blended-refuge and block-refuge strains, data are for larvae reared on either pure $B t$ corn (pure-Bt strain and block-refuge strain) or a blend of $90 \% B t$ corn and $10 \%$ non-Bt corn (blended-refuge strain). For the unselected strain, larvae were reared on non-Bt corn. Data are presented for generations in which selection was imposed ( $F$ represents the absolute generation; $S$ represents the numbers of selected generations). Sample means are shown, and error bars are the standard error of the mean. Letters indicate significant differences among strains within a generation. For proportional survival to adulthood, corrected survival for block-refuge, blended-refuge and pure- $B t$ strains was calculated as the proportional survival for the selected strain on $B t$ treatments divided by the proportional survival of the unselected strain on non- $B t$ corn during each generation.

sizes among strains were not the same. The sample sizes for pairs of $B t$ and non- $B t$ seedling mats were as follows: unselected strain $=17$, block-refuge strain $=20$, blended-refuge strain $=20$, and pure- $B$ t strain $=19$, for a total of 152 seedling mats tested. Because several of the $B t$ seedling mats did not produce adult insects, as expected given the level of larval mortality imposed by Cry34/35Ab1 corn, ${ }^{27,41}$ measurements of developmental rate on $B t$ corn were based on the following sample sizes: unselected strain $=2$, block-refuge strain $=15$, blended-refuge strain $=18$, and pure- $B t$ strain $=18$, for a total of 106 seedling mats.

\subsection{Data analysis}

All statistical analyses were performed in R 2.15.0,42 using aov for analysis of variance (ANOVA) and pairwise.t.test for pairwise tests with no adjustment method (which performs pairwise comparisons using $t$-tests with a pooled standard deviation); adjustments
Table 1. Analysis of variance for corrected survival of pure- $B t$, blended-refuge and block-refuge strains on Bt corn

\begin{tabular}{llrr} 
Generation & df & $F$ & $P^{\mathrm{a}}$ \\
\hline F4 & 2,69 & 38.57 & $<0.0001^{*}$ \\
F5 & 2,50 & 13.44 & $<0.0001^{*}$ \\
F8 & 2,59 & 13.33 & $<0.0001^{*}$ \\
F9 & 5.95 & 0.00986 \\
F10 & 2,19 & 74.33 & $<0.0001^{*}$ \\
F11 & 2,73 & 25.74 & $<0.0001^{*}$ \\
F13 & 2,69 & 19.58 & $<0.0001^{*}$ \\
F15 & 2,95 & 43.94 & $<0.0001^{*}$ \\
\hline
\end{tabular}

a * Indicates significant differences. See Figs 2 and 3 for differences among strains.

for multiple comparisons were made by adjusting the alpha as stated below for each set of comparisons.

For survival during strain selection, the variance of the unselected strain was much greater than that of the other three strains. Therefore, we calculated corrected survival of the block-refuge, blended-refuge and pure- $B t$ strains in each generation as proportional survival for each seedling mat (i.e. proportion of eggs that yielded adult insects) divided by the average proportional survival of the unselected strain in that generation (results reported in Fig. 1a). Then, we used ANOVA to compare corrected survival among the selected strains (block refuge, blended refuge and pure $B t$ ) within each generation during only the generations that underwent selection (Bonferroni correction was used to adjust the alpha level for eight generations of selection, adjusted alpha $=0.006$ ). If strains were significantly different, which occurred in seven of eight generations (Table 1), we performed pairwise comparisons among strains within a generation (after Bonferroni correction for 21 pairwise comparisons, adjusted alpha $=0.002$ ).

For days to adult emergence during strain selection, we used ANOVA to compare all four strains within each generation during only the generations that underwent selection (results reported in Fig. 1b; after Bonferroni correction for eight generations of selection, adjusted alpha $=0.006$ ). If strains were significantly different, which occurred in six of eight generations, we performed pairwise comparisons among strains within a generation (after Bonferroni correction for 36 comparisons, adjusted alpha $=0.001)$.

Because larvae from each of the four treatments were placed onto paired $B t$ and non-Bt seedling mats for bioassays measuring larval development and survival to adulthood, we standardized measurements on $B t$ corn by measurements obtained for non-Bt corn. For the larval development bioassay, we subtracted the proportion of third-instar larvae on Bt corn from the proportion of third-instar larval on non-Bt corn (results reported in Fig. 2). For the adult survival bioassay, we subtracted proportional mortality on $B t$ corn from proportional mortality on non-Bt corn, and for measurements of days to adult emergence we subtracted days to emergence on non-Bt corn from days to emergence on $B t$ corn (results reported in Fig. 3). Data for all bioassays were compared among all four strains (unselected, block refuge, blended refuge and pure $B t$ ) using ANOVA. If strains were significantly different, we performed pairwise comparisons among the four strains, with an adjusted alpha $=0.008$ based on a Bonferroni correction for six pairwise comparisons. 

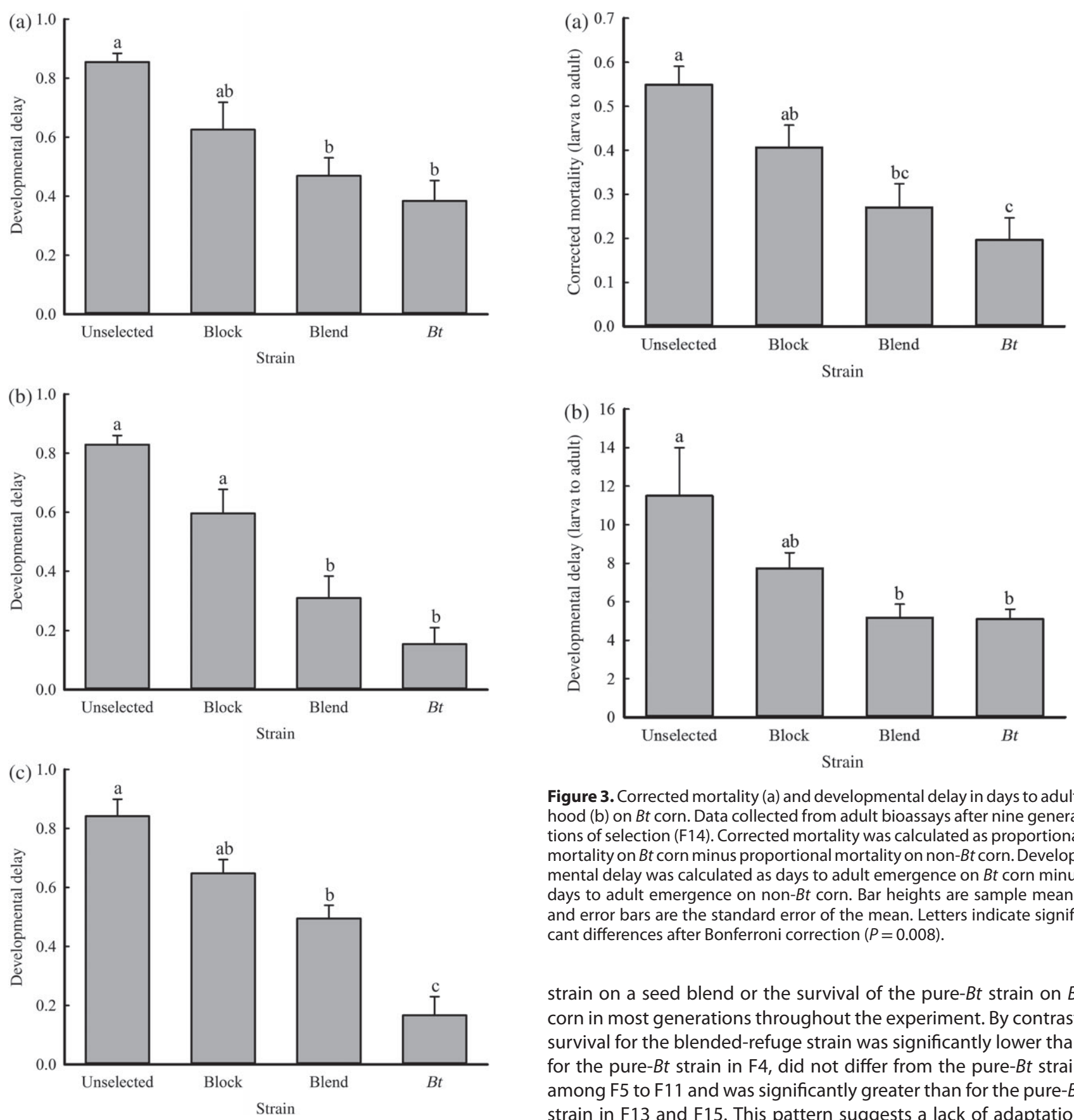

Figure 2. Developmental delay on Bt corn in larval bioassays. Developmental delay (a) after four generations of selection (F5, F6 and F7), (b) after seven generations of selection (F10) and (C) after nine generations of selection (F14). Developmental delay was calculated as the proportion of third-instar larvae on non-Bt corn minus the proportion of third instars on $B t$ corn. Bar heights are sample means, and error bars are the standard error of the mean. Letters indicate significant differences after Bonferroni correction $(P=0.008)$.

\section{RESULTS}

\subsection{Strain selection: survival and development time}

When we compared survival within generations among the three selected strains after correcting for survival in the unselected strain, strains were significantly different in each generation except F9 (Table 1, Fig. 1a). Survival of the block-refuge strain on Bt corn was significantly lower than the survival of the blended-refuge

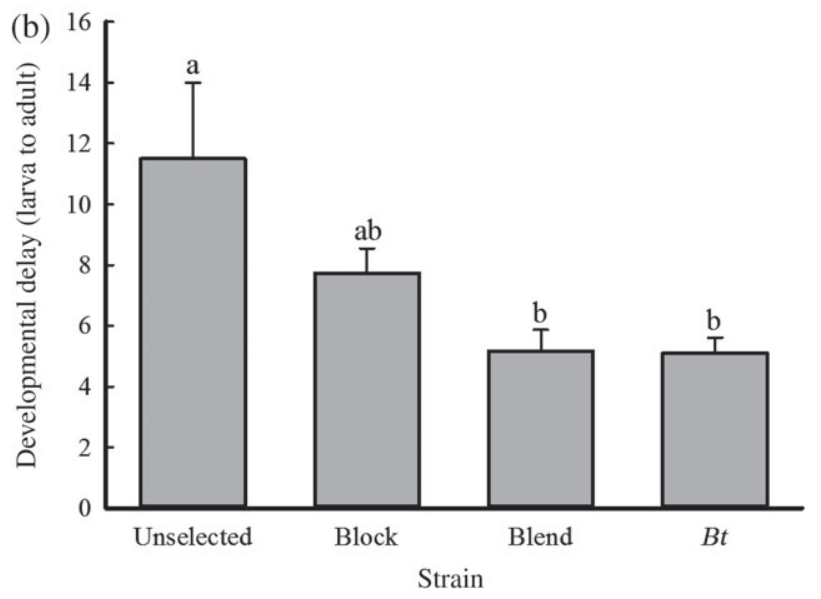

Figure 3. Corrected mortality (a) and developmental delay in days to adulthood (b) on Bt corn. Data collected from adult bioassays after nine generations of selection (F14). Corrected mortality was calculated as proportional mortality on Bt corn minus proportional mortality on non-Bt corn. Developmental delay was calculated as days to adult emergence on $B t$ corn minus days to adult emergence on non-Bt corn. Bar heights are sample means, and error bars are the standard error of the mean. Letters indicate significant differences after Bonferroni correction $(P=0.008)$.

strain on a seed blend or the survival of the pure-Bt strain on $B t$ corn in most generations throughout the experiment. By contrast, survival for the blended-refuge strain was significantly lower than for the pure-Bt strain in F4, did not differ from the pure-Bt strain among $\mathrm{F} 5$ to $\mathrm{F} 11$ and was significantly greater than for the pure- $B t$ strain in F13 and F15. This pattern suggests a lack of adaptation to $B t$ corn by the block-refuge strain, but adaptation to the seed blend by the blended-refuge strain.

Days to emergence differed among strains except during F8 and F9 (Table 2, Fig. 1b). In general, the block-refuge strain on $B t$ corn required the longest time before adults emerged, while no differences were observed among the unselected strain on non-Bt corn, the pure- $B t$ strain on $B t$ corn and the blended-refuge strain on the seed blend. This suggests a lack of adaptation in the block-refuge strain, but adaptation to the seed blend by the blended-refuge strain, and adaptation to $B t$ corn by the pure-Bt strain.

\subsection{Larval development bioassay}

Developmental delay to third instar describes the difference in the proportion of third-instar larvae found on Bt corn compared 


\begin{tabular}{|lccc|}
\hline \multicolumn{4}{l}{$\begin{array}{l}\text { Table 2. Analysis of variance for time until adult emergence among } \\
\text { strains within a generation when strains experienced selection }\end{array}$} \\
Generation & df & $F$ & $P^{\mathrm{a}}$ \\
\hline F4 & 3,25 & 7.94 & $0.0007^{*}$ \\
F5 & 3,29 & 20.30 & $<0.0001^{*}$ \\
F8 & 3,26 & 3.20 & 0.04 \\
F9 & 3,21 & 1.37 & 0.279 \\
F10 & 3,23 & 7.64 & $0.001^{*}$ \\
F11 & 3,40 & 20.16 & $<0.0001^{*}$ \\
F13 & 3,40 & 7.08 & $0.0006^{*}$ \\
F15 & 3,35 & 14.87 & $<0.0001^{*}$ \\
\hline
\end{tabular}

a * Indicates significant differences after Bonferroni correction (adjusted alpha $=0.006$ ). See Fig. $1 \mathrm{~b}$ for differences among strains.

with non-Bt corn, with 0 indicating no difference in the proportion of third-instar larvae found on $B t$ versus non-Bt seedling mats. Significant differences were found among strains for developmental delays to third instar when testing strains after four generations of selection (i.e. combining data from F5, F6 and F7 (Table 3, Fig. 2a). Development to third instar on Bt corn was significantly delayed in the unselected strain compared with the blended-refuge strain and the pure-Bt strain (Fig. 2a), indicating statistically significant and similar adaptation to $B t$ corn in the pure- $B t$ strain and blended-refuge strain, but a lack of adaptation by the block-refuge strain.

Strains also differed after seven generations of selection (F10), with the unselected and block-refuge strains having significantly greater developmental delay compared with the blended-refuge and pure- $B t$ strains (Table 3, Fig. 2 b), suggesting a similar pattern of adaptation to that observed after four generations of selection.

Following nine generations of selection (F14), developmental delay was significantly greater for the unselected strain than for the blended-refuge and pure-Bt strains. The block-refuge and blended-refuge strains did not differ from each other and showed a greater developmental delay than the pure-Bt strain (Table 3, Fig. 2c). These results indicate similar levels of resistance after nine generations of selection for the blended and block refuges, and significantly lower levels of resistance in these strains than was observed in the absence of a refuge.

\subsection{Adult survival bioassays}

We compared the difference in mortality from larva to adult between $B t$ corn and non-Bt corn (i.e. mortality imposed by $B t$ corn) among strains after nine generations of selection (F14) and found significant differences (Table 3, Fig. 3a). Mortality imposed by $B t$ corn was greatest for the unselected strain and did not differ between the unselected strain and the block-refuge strain. By contrast, mortality imposed by $B t$ corn for both the blended-refuge strain and the pure-Bt strain did not differ significantly and was significantly less than for the unselected strain. These results suggest that the block refuge delayed resistance compared with an absence of refuges, and that some adaptation to $B t$ corn occurred for the blended-refuge strain, although the level of resistance did not differ from that of the block-refuge strain (Fig. 3a).

Strains also differed in developmental delay to adulthood (Table 3, Fig. 3b). Developmental delay was greater for the unselected strain than for the blended-refuge strain and the pure-Bt strain, but the block-refuge strain was intermediate and did not differ from any of the other strains (Fig. 3b). This result indicates that the block refuge delayed the development of resistance, but resistance in the blended refuge was similar to that observed in the absence of refuges.

\section{DISCUSSION}

In this study, we used an experimental evolution approach to test whether refuges can delay resistance of $D$. v. virgifera to corn producing Bt toxin Cry34/35Ab1 (event DAS-59122-7), which is a non-high-dose $B t$ hybrid. ${ }^{11,32}$ Refuges are most effective for delaying resistance when $B t$ crops produce a high dose of toxin, which kills heterozygous resistant individuals. ${ }^{43}$ We found evidence that refuges could delay resistance, and that under the parameters studied here the block refuge was more effective than the blend refuge at delaying resistance.

There were several important differences between our study and conditions in the field that likely contributed to the results observed here. Firstly, in the block-refuge treatment, refuge individuals were added to adult population cages at the same time as Bt-selected individuals. This enabled complete random mating between refuge individuals and Bt-selected individuals. By contrast, in the field (and shown in our data, Fig. 2), the delayed emergence of individuals from $B t$ corn compared with non- $B t$ $\operatorname{corn}^{27,29}$ and the limited dispersal of adults from refuges to $B t$ fields ${ }^{44}$ would lead to non-random assortative mating among $B$-selected individuals and accelerate resistance evolution. In our selection experiment, these differences in space and time were not present because we placed refuge insects and selected insects into adult cages at the same time, making random mating more likely than it might be in the field.

Secondly, with the block-refuge treatment, the refuge population was never exposed to Bt corn. In the field, resistance evolves through dispersal of $B t$-selected individuals into refuge populations. ${ }^{45}$ Over time, the accumulation of resistance alleles within refuge populations disrupts the dynamic of homozygous susceptible refuge individuals mating with the $B t$-selected individuals and leads to the evolution of resistance. Additionally, the population starting each generation within the block-refuge strain consisted of $10 \%$ adults emerging from Bt corn (presumably possessing resistance traits) and $90 \%$ adults emerging from non- $B t$ corn. This ratio is consistent with emergence of insects reported in Storer et al., ${ }^{27}$ assuming a landscape with $80 \%$ Cry34/35Ab1 corn and $20 \%$ non-Bt corn. However, if survival on Bt corn in the field is greater than this, as has been found elsewhere, ${ }^{32}$ the rate of resistance evolution in a field setting may be greater than found in this experiment.

Conversely, in the blended refuge studied here, the close proximity of $B t$ to non-Bt corn in the blended refuge likely caused more larvae to be exposed to $B t$ corn than would occur in a field setting. Past studies of $D$. v. virgifera have determined that larvae can move between $B t$ and non- $B$ t corn roots. ${ }^{46,47}$ In our blended-refuge treatment, non- $B t$ and $B t$ corn seeds were mixed within small containers. This experimental approach likely allowed for more larval movement between non-Bt and Bt corn roots than would be expected in the field because roots for both types of corn were contained in close proximity within larval rearing seed mats. This in turn likely increased the intensity of selection and the rate of resistance evolution. Additionally, it is possible that, in some cases, larvae may have consumed all of the non-Bt roots and then were forced to feed on Bt roots, a situation that would only arise at very high pest densities in the field. These factors may have 
Table 3. Analysis of variance for bioassays

\begin{tabular}{|c|c|c|c|c|c|}
\hline Life stage & Response factor & Generation & $\mathrm{df}$ & $F$ & $p^{a}$ \\
\hline Larval & Developmental delay & F5, F6, F7 & 3,114 & 10.67 & $<0.0001^{*}$ \\
\hline Larval & Developmental delay & F10 & 3,73 & 22.46 & $<0.0001^{*}$ \\
\hline Larval & Developmental delay & F14 & 3,68 & 26.96 & $<0.0001^{*}$ \\
\hline Adult & Mortality & F14 & 3,72 & 9.25 & $<0.0001^{*}$ \\
\hline Adult & Developmental delay & F14 & 3,49 & 5.66 & $0.002^{*}$ \\
\hline
\end{tabular}

a * Indicates significant differences. See Figs 2 and 3 for differences among strains.

contributed to the similarity in resistance development between our blended-refuge and pure- $B t$ strains in this study.

Diabrotica $v$. virgifera has exhibited evolution of resistance to $B t$ toxins in both the laboratory and the field. Several studies have found that laboratory-selected strains of D. v. virgifera evolved resistance to Cry3Bb1 in as few as three generations of selection, ${ }^{18,48}$ and the discovery of field-evolved resistance to Cry3Bb1 illustrated a similar pattern of resistance evolution. ${ }^{10-13}$ Furthermore, our study, as well as Lefko et al., ${ }^{19}$ demonstrates that $D$. v. virgifera has the potential to evolve resistance to the Cry34/35Ab1 toxin. Nonetheless, we found evidence that refuges of non-Bt corn can delay $B t$ resistance in $D$. v. virgifera, even though $B t$ corn targeting $D$. v. virgifera is not high dose (unselected strain versus block-refuge strain, Figs 2 and 3). However, this was associated with large populations of susceptible (unselected) insects that mated synchronously and randomly with Bt-selected individuals. To the extent that these conditions are not met in the field, more rapid resistance evolution is expected.

Refuges can delay the evolution of resistance in pest species, and this strategy is most effective when resistance alleles are rare and inherited recessively. ${ }^{23}$ The high-dose refuge strategy has been effective for managing $B t$ resistance in O. nubilalis, ${ }^{4}$ likely in part because resistance alleles enabling survival of $O$. nubilalis on $B t$ plants appear to be rare. ${ }^{49,50}$ However, simulation studies show that, when resistance is only partially recessive or additive, resistance can develop at a faster rate than when resistance is functionally recessive. ${ }^{23} B t$ corn used to manage $D$. v. virgifera does not produce a high dose of $B t$ toxin, ${ }^{18,26,27,31}$ and, as expected, resistance to $B t$ corn by $D$. v. virgifera has been found to be non-recessive. ${ }^{18}$ Furthermore, the rate of resistance evolution increases as the initial resistance allele frequency becomes greater, ${ }^{1,16}$ and in $D$. $v$. virgifera the resistance allele frequency has been estimated to be 2000 times greater than frequencies typically assumed to exist in a pest population prior to commercialization of a $B t$ crop. $^{16}$ Both the lack of a high dose and the greater prevalence of resistance alleles will increase the risk that populations of $D$. $v$. virgifera will evolve resistance to $B t$ corn.

Another strategy to delay the evolution of resistance is pyramiding of $B t$ toxins that target the same species. ${ }^{51}$ Delays in resistance arise from pyramiding because one $B t$ toxin within a pyramid (e.g. toxin A) should kill all individuals susceptible to that $B t$ toxin, including those individuals that harbour resistance alleles to the other Bt toxin (e.g. toxin B) present in the pyramid. ${ }^{51}$ The same reciprocal effect of toxin $B$ on resistance alleles for toxin $A$ is expected. Furthermore, most individuals targeted by the pyramid are susceptible to each $B t$ toxin and are therefore killed by each toxin, also known as 'redundant killing'. ${ }^{52}$ Pyramids are currently used in combination with refuges, although refuge requirements are reduced from 20 to $5 \%$ for $B t$ corn pyramids. ${ }^{53}$ Successful management of pests by pyramiding $B t$ toxins depends on how effective each toxin is at killing the targeted species, and the frequency of resistance alleles at the time a pyramid is deployed. ${ }^{13}$

The use of $B t$ corn is advantageous because it can reduce the reliance on broad-spectrum conventional insecticides for managing pests. ${ }^{3}$ However, D. v. virgifera has demonstrated an ability to evolve resistance to management practices including Bt corn..$^{8-11}$ For cases where $B t$ toxins are not high dose, pyramiding multiple $B t$ toxins can achieve greater delays in resistance than when toxins are used individually. ${ }^{51}$ Additionally, the use of more diversified management tactics, as part of an integrated approach to pest management, may also help to reduce the risk of resistance evolution.

\section{ACKNOWLEDGEMENTS}

We thank the Gassmann lab at lowa State University for reading previous drafts of this manuscript, and DuPont-Pioneer for providing the corn seed used in this study. This research was supported by Biotechnology Risk Assessment Grant Program competitive grant no. 2009-33120-20256 from the USDA National Institute of Food and Agriculture. Mention of trade names or commercial products in this publication is solely for the purpose of providing specific information and does not imply recommendation or endorsement by lowa State University or the US Department of Agriculture.

\section{REFERENCES}

1 Gould F, Sustainability of transgenic insecticidal cultivars: integrating pest genetics and ecology. Annu Rev Entomol 43(1):701 - 726 (1998).

2 Acreage (June 2013). National Agriculture Statistics Service, USDA, Washington, DC (2013).

3 Cattaneo MG, Yafuso C, Schmidt C, Huang CY, Rahman M, Olson C et al., Farm-scale evaluation of the impacts of transgenic cotton on biodiversity, pesticide use, and yield. Proc Natl Acad Sci USA 103(20):7571 - 7576 (2006).

4 Hutchison WD, Burkness EC, Mitchell PD, Moon RD, Leslie TW, Fleischer $\mathrm{SJ}$ et al., Areawide suppression of European corn borer with $B t$ maize reaps savings to non-Bt maize growers. Science 330(6001):222-225 (2010).

5 Gray ME, Sappington TW, Miller NJ and Bohn MO, Adaptation and invasiveness of western corn rootworm: intensifying research on a worsening pest. Annu Rev Entomol 54:303-321 (2009).

6 Cullen EM, Gray ME, Gassmann AJ and Hibbard BE, Resistance to Bt corn by western corn rootworm (Coleoptera: Chrysomelidae) in the US Corn Belt. J Integr Pest Manag 4(3):D1 -D6 (2013).

7 Parimi S, Meinke LJ, French BW, Chandler LD and Siegfried BD, Stability and persistence of aldrin and methyl-parathion resistance in western corn rootworm populations (Coleoptera: Chrysomelidae). J Econ Entomol 25(3):269-274 (2006).

8 Meinke LJ, Siegfried BD, Wright RJ and Chandler LD, Adult susceptibility of Nebraska western corn rootworm (Coleoptera: Chrysomelidae) 
populations to selected insecticides. J Econ Entomol 91(3):594-600 (1998).

9 Levine E, Spencer JL, Isard SA, Onstad DW and Gray ME, Adaptation of the western corn rootworm to crop rotation: evolution of a new strain in response to a management practice. Am Entomol 48(2):94-107 (2002).

10 Gassmann AJ, Petzold-Maxwell JL, Keweshan RS and Dunbar MW, Field-evolved resistance to $B t$ maize by western corn rootworm. PLoS ONE 6(7):e22629 (2011).

11 Gassmann AJ, Field-evolved resistance to $B t$ maize by western corn rootworm: predictions from the laboratory and effects in the field. J Invertebr Pathol 110(3):287-293 (2012).

12 Gassmann AJ, Petzold-Maxwell JL, Keweshan RS and Dunbar MW, Western corn rootworm and $B t$ maize: challenges of pest resistance in the field. GM Crops Food 3(3):235-244 (2012).

13 Gassmann AJ, Petzold-Maxwell JL, Clifton EH, Dunbar MW, Hoffmann AM, Ingber DA et al., Field-evolved resistance by western corn rootworm to multiple Bt toxins in transgenic maize. Proc Natl Acad Sci USA 111(14):5141-5146 (2014).

14 Onstad DW and Gould F, Do dynamics of crop maturation and herbivorous insect life cycle influence the risk of adaptation to toxins in transgenic host plants? Environ Entomol 27(3):517-522 (1998).

15 Onstad DW, Guse CA, Spencer JL, Levine E and Gray ME, Modeling the dynamics of adaptation to transgenic corn by western corn rootworm (Coleoptera: Chrysomelidae). J Econ Entomol 94(2):529-540 (2001).

16 Onstad DW and Meinke LJ, Modeling evolution of Diabrotica virgifera virgifera (Coleoptera: Chrysomelidae) to transgenic corn with two insecticidal traits. J Econ Entomol 103(3):849-860 (2010).

17 Tabashnik BE, Delaying insect resistance to transgenic crops. Proc Natl Acad Sci USA 105(49):19 029-19030 (2008).

18 Meihls LN, Higdon ML, Siegfried BD, Miller NJ, Sappington TW, Ellersieck MR et al., Increased survival of western corn rootworm on transgenic corn within three generations of on-plant greenhouse selection. Proc Natl Acad Sci USA 105(49):19 177-19 182 (2008).

19 Lefko SA, Nowatzki TM, Thompson SD, Binning RR, Pascual MA, Peters $\mathrm{ML}$ et al., Characterizing laboratory colonies of western corn rootworm (Coleoptera: Chrysomelidae) selected for survival on maize containing event DAS-59122-7. J Appl Entomol 132(3):189-204 (2008).

20 Meihls LN, Higdon ML, Ellersieck M and Hibbard BE, Selection for resistance to $\mathrm{mCry3} \mathrm{A}$-expressing transgenic corn in western corn rootworm. J Econ Entomol 104(3):1045-1054 (2011).

21 Frank DL, Zukoff A, Barry J, Higdon ML and Hibbard BE, Development of resistance to eCry3.1Ab-expressing transgenic maize in a laboratory-selected population of western corn rootworm (Coleoptera: Chrysomelidae). J Econ Entomol 106:2506-2513 (2013).

22 Mallet $J$ and Porter $P$, Preventing insect adaptation to insect-resistant crops: are seed mixtures or refugia the best strategy? Proc R Soc B Biol Sci 250(1328):165-169 (1992).

23 Tabashnik $B E$, Delaying insect adaptation to transgenic plants: seed mixtures and refugia reconsidered. Proc $R$ Soc $B$ Biol Sci 255(1342):7-12 (1994).

24 Carriere Y, Crowder DW and Tabashnik BE, Evolutionary ecology of insect adaptation to Bt crops. Evol Applic 3(5-6):561-573 (2010).

25 Final Report of the FIFRA Scientific Advisory Panel: Subpanel on Bacillus thuringiensis (Bt) Plant-pesticides and Resistance Management. [Online]. EPA. Available: http://www.epa.gov/scipoly/sap/ meetings/1998/february/finalfeb.pdf [14 October 2013].

26 Hibbard BE, Meihls LN, Ellersieck MR and Onstad DW, Densitydependent and density-independent mortality of the western corn rootworm: impact on dose calculations of rootworm-resistant $B t$ corn. J Econ Entomol 103(1):77-84 (2010).

27 Storer NP, Babcock JM and Edwards JM, Field measures of western corn rootworm (Coleoptera: Chrysomelidae) mortality caused by Cry34/35Ab1 proteins expressed in maize event 59122 and implications for trait durability. J Econ Entomol 99(4):1381-1387 (2006).

28 Hibbard BE, Clark TL, Ellersieck MR, Meihls LN, El Khishen AA, Kaster $\mathrm{V}$ et al., Mortality of western corn rootworm larvae on MIR604 transgenic maize roots: field survivorship has no significant impact on survivorship of F1 progeny on MIR604. J Econ Entomol 103(6):2187-2196 (2010)

29 Hibbard BE, Frank DL, Kurtz R, Boudreau E, Ellersieck MR and Odhiambo JF, Mortality impact of $B t$ transgenic maize roots expressing eCry3.1 Ab, mCry3A, and eCry3.1Ab plus mCry3 A on western corn rootworm in the field. J Econ Entomol 104(5):1584-1591 (2011).
30 Clark TL, Frank DL, French BW, Meinke LJ, Moellenbeck D, Vaughn TT et al., Mortality impact of MON863 transgenic maize roots on western corn rootworm larvae in the field. J Appl Entomol 136(10):721-729 (2012).

31 Petzold-Maxwell JL, Cibils-Stewart X, French BW and Gassmann AJ, Adaptation by western corn rootworm (Coleoptera: Chrysomelidae) to $B t$ maize: inheritance, fitness costs, and feeding preference. J Econ Entomol 105(4):1407-1418 (2012).

32 Petzold-Maxwell JL, Jaronski ST, Clifton EH, Dunbar MW, Jackson MA and Gassmann AJ, Interactions among Bt maize, entomopathogens, and rootworm species (Coleoptera: Chrysomelidae) in the field: effects on survival, yield, and root injury. J Econ Entomol 106(3):622-632 (2013).

33 Pan Z, Onstad DW, Nowatzki TM, Stanley BH, Meinke LJ and Flexner JL, Western corn rootworm (Coleoptera: Chrysomelidae) dispersal and adaptation to single-toxin transgenic corn deployed with block or blended refuge. Environ Entomol 40(4):964-978 (2011).

34 Nowatzki TM, Lefko SA, Binning RR, Thompson SD, Spencer TA and Siegfried BD, Validation of a novel resistance monitoring technique for corn rootworm (Coleoptera: Chrysomelidae) and event DAS-59122-7 maize. J Appl Entomol 132(3):177-188 (2008).

35 Meihls LN, Higdon ML, Ellersieck MR, Tabashnik BE and Hibbard $\mathrm{BE}$, Greenhouse-selected resistance to Cry3Bb1-producing corn in three western corn rootworm populations. PLoS ONE 7(12): e51055 (2012).

36 Kim KS, French BW, Sumerford DV and Sappington TW, Genetic diversity in laboratory colonies of western corn rootworm (Coleoptera: Chrysomelidae), including a nondiapause colony. Environ Entomol 36:637-645 (2007).

37 Branson TF, The selection of a non-diapausing strain of Diabrotica virgifera (Coleoptera: Chrysomelidae). Entomol Exp Applic 19:148-154 (1976).

38 Jackson JJ, Diabrotica spp., in Handbook of Insect Rearing, ed. by Singh P and Moore RF. Elsevier, New York (1985).

39 Review of Corn Rootworm Resistance Monitoring Submissions and Data (2009-2011) for Bt Corn Products Containing Cry34/35Ab1. [Online]. EPA. Available: http://www.regulations.gov/\#!document Detail;D=EPA-HQ-OPP-2011-0922-0042 [21 March 2014].

40 Hammack L, Ellsbury MM, Roehrdanz RL and Pikul JL, Larval sampling and instar determination in field populations of northern and western corn rootworm (Coleoptera: Chrysomelidae). J Econ Entomol 96(4):1153-1159 (2003).

41 Petzold-Maxwell JL, Jaronski ST and Gassmann AJ, Tritrophic interactions among $B t$ maize, an insect pest and entomopathogens: effects on development and survival of western corn rootworm. Ann Appl Biol 160(1):45-55 (2012).

42 R: a Language and Environment for Statistical Computing. Version 3.1.0. [Online]. R Development Core Team, R Foundation for Statistical Computing, Vienna, Austria (2014). Available: http://cran.r-project.org/ [4 March 2014].

43 Tabashnik BE, Gassmann AJ, Crowder DW and Carrière $\mathrm{Y}$, Insect resistance to $B t$ crops: evidence versus theory. Nat Biotechnol 26(2):199-202 (2008).

44 Spencer JL, Hibbard BE, Moeser J and Onstad DW, Behaviour and ecology of the western corn rootworm (Diabrotica virgifera virgifera LeConte). Agric For Entomol 11(1):9-27 (2009).

45 Comins $\mathrm{HN}$, The development of insecticide resistance in the presence of migration. J Theor Biol 64(1):177-197 (1977).

46 Hibbard BE, Vaughn TT, Oyediran IO, Clark TL and Ellersieck MR, Effect of Cry3Bbl-expressing transgenic corn on plant-to-plant movement by western corn rootworm larvae (Coleoptera: Chrysomelidae). $J$ Econ Entomol 98(4):1126-1138 (2005).

47 Zukoff SN, Bailey WC, Ellersieck MR and Hibbard BE, Western corn rootworm larval movement in SmartStax seed blend scenarios. $J$ Econ Entomol 105(4):1248-1260 (2012).

48 Oswald KJ, French BW, Nielson C and Bagley M, Selection for Cry3Bb1 resistance in a genetically diverse population of nondiapausing western corn rootworm (Coleoptera: Chrysomelidae). J Econ Entomol 104(3): 1038-1044 (2011)

49 Alves AP, Spencer TA, Tabashnik BE and Siegfried BD, Inheritance of resistance to the Cry1 $\mathrm{Ab}$ Bacillus thuringiensis toxin in Ostrinia nubilalis (Lepidoptera: Crambidae). J Econ Entomol 99(2):494-501 (2006).

50 Andow DA, Alstad DN, Pang YH, Bolin PC and Hutchison WD, Using an F-2 screen to search for resistance alleles to Bacillus thuringiensis 
toxin in European corn borer (Lepidoptera: Crambidae). J Econ Entomol 91(3):579-584 (1998).

51 Roush RT, Two-toxin strategies for management of insecticidal transgenic crops: can pyramiding succeed where pesticide mixtures have not? Phil Trans R Soc Lond Ser B Biol Sci 353(1376):1777-1786 (1998).
52 Comins HN, Tactics for resistance management using multiple pesticides. Agric Ecosyst Environ 16(2):129-148 (1986).

53 Pesticide Fact Sheet. MON 89034 TC1507 MON 88017 DAS-59122-7. [Online]. EPA. Available: http://www.epa.gov/oppbppd1/ biopesticides/pips/smartstax-factsheet.pdf [23 October 2014]. 